\title{
A formação de professores da educação profis- sional como objeto de estudo dos Programas de Pós-Graduação no Brasil
}

\author{
Marilandi Maria Mascarello Vieira \\ Josimar de Aparecido Vieira \\ Instituto Federal de Educação, Ciência e Tecnologia do Rio Grande do Sul \\ Maria Cristina Pansera de Araújo \\ Universidade Regional do Noroeste do Estado do Rio Grande do Sul
}

\section{Resumo}

Este artigo apresenta pesquisa meta-analítica que objetivou descrever e analisar os trabalhos apresentados aos programas de Pós-Graduação no período de 2010 a 2017 que tratam da formação de professores para a educação profissional (EP). Trata-se de pesquisa qualitativa, de caráter bibliográfico e documental e o corpus foi constituído de 56 trabalhos. A análise de dados toma como referência Bardin (2002) e foram delineadas três categorias: características gerais da produção; temáticas investigadas e referencial teórico; percurso metodológico. Os resultados indicam acentuado crescimento de pesquisas sobre o tema; as temáticas recorrentes foram: a) processo de constituição da docência/saberes docentes na EP; b) políticas de formação dos seus professores; c) análise de programas ou cursos de formação de professores; d) relação entre formação e trabalho docente. $\bigcirc$ percurso metodológico caracteriza-se como pesquisas qualitativas, predominantemente de campo e bibliográficas. $\bigcirc$ lócus foram os Institutos Federais de Educação e o instrumento mais utilizado foi a entrevista com professores que atuam na EP. Palavras-chave: Educação profissional. Formação de professores. Meta-análise. Cursos técnicos.

\section{The training of professional education teachers as object of study of the Graduate Programs in Brazil}

\section{Abstract}

This article presents a meta-analytic research that aims to describe and analyze the papers presented to the Graduate programs in the period from 2010 to 2017 that deal with the teachers training for professional education (PE). It is a qualitative research, of bibliographical and documentary character, and the corpus was constituted of 56 works. Data analysis takes as reference Bardin (2002) and was outlined three categories: general characteristics of production; researched topics and theoretical referential; methodological approach. The results indicate a strong growth of research on the subject; the recurrent themes were: a) process of constitution of the teaching / teachers' knowledge in the PE; b) training policies of their teachers; c) analysis of teacher training programs or courses; d) relationship between formation and teachers work. The methodological course is characterized as qualitative research, predominantly of field and bibliographical. The locus were the Federal Institutes of Education and the most used instrument was the interview with teachers who works in the PE.

Keywords: Professional education. Teacher training. Meta-analysis. Technical courses. 
A formação de professores da educação profissional como objeto de estudo dos Programas de Pós-Graduação no Brasil

\section{La formación de profesores de educación profesional como objeto de estudio de los Programas de Postgrado en Brasil}

\section{Resumen}

Este artículo presenta la investigación meta-analítica que objetivó describir y analizar los trabajos presentadas a los programas de postgrado en el período entre 2010 y 2017 que tratan de la formación de profesores para la educación profesional (EP). Se trata de investigación cualitativa, de carácter bibliográfico y documental y el corpus fue constituido de 56 trabajos. El análisis de datos toma como referencia Bardin (2002) y se han delineado tres categorías: características generales de la producción; temáticas investigadas y referencial teórico; recorrido metodológico. Los resultados indican un acentuado crecimiento de investigaciones sobre el tema; los temas recurrentes fueron: a) proceso de constitución de la docencia/saberes docentes em la EP; b) políticas de formación de sus profesores; c) análisis de programas o cursos de formación de sus profesores; d) relación entre formación y trabajo docente. El recorrido metodológico se caracteriza como investigaciones cualitativas, predominantemente de campo y bibliográficas. El locus fueron los institutos federales de educación y el instrumento más utilizado fue la entrevista con profesores que actúan en la EP.

Palabras clave: Educación profesional. Formación de profesores. Meta-análisis. Cursos técnicos.

\section{Introdução}

A análise da produção acadêmica sobre educação profissional e formação de seus professores tem sido objeto de estudos anteriores (VIEIRA, 2018; VIEIRA, ARAÚjO, CARVALHO, PEREIRA, 2018) e, com este artigo, almejamos complementar a análise iniciada, descrevendo e analisando as produções acadêmicas oriundas dos Programas de Pós-Graduação no Brasil.

A intencionalidade de mapear os estudos sobre o tema adveio da constatação de pouca produção acadêmica sobre ele no período anterior a 2010, conforme apontaram os trabalhos de Pena (2011) e Baptaglin (2013).

Esse tipo de estudo é chamado de "meta-análise", "pesquisa sobre pesquisa", "estado da arte" ou "estado do conhecimento". A contribuição desse tipo de investigação é ressaltada por Romanowski; Ens:

O interesse por pesquisas que abordam "estado da arte" deriva da abrangência desses estudos para apontar caminhos que vêm sendo tomados e aspectos que são abordados em detrimento de outros. A realização destes balanços possibilita contribuir com a organização e análise na definição de um campo, uma área, além de indicar possíveis contribuições da pesquisa para com as 
rupturas sociais. A análise do campo investigativo é fundamental neste tempo de intensas mudanças associadas aos avanços crescentes da ciência e da tecnologia (ROMANOWSKI; ENS, 2006, p. 39).

Assim, analisamos as teses e dissertações produzidas nos Programas de Pós-Graduação que tratam da formação inicial de professores da EP entre 2010 a 2017, norteada pela seguinte questão: como está sendo abordada a formação de professores para a EP, nas pesquisas produzidas nos Programas de Pós-Graduação no Brasil?

Consultamos o site da Coordenação de Aperfeiçoamento de Pessoal de Nível Superior (Capes), dos Programas de Pós-Graduação e da Biblioteca Digital Brasileira de Teses e Dissertações do Instituto Brasileiro de Informação em Ciência e Tecnologia (IBICT). A tarefa foi orientada por dois critérios: o recorte cronológico (2010-2017), pois essa era uma lacuna encontrada nas publicações sobre o tema, e a centralidade dos estudos na formação de professores para a educação profissional técnicas de nível médio. Para localização dos estudos, usamos os descritores educação profissional - formação de professores - cursos técnicos, que possibilitaram identificar 56 trabalhos ( 16 teses e 40 dissertações) que constituíram o corpus da pesquisa. Os dados constam no quadro em apêndice.

Nos trabalhos foi lido o resumo, introdução, conclusões/ considerações finais e, quando as informações não estavam claras, procedeu-se à leitura flutuante (Bardin, 2002) do conteúdo das produções. As informações foram transcritas para uma planilha do Microsoft Excel visando facilitar a categorização, realizada por meio da análise de conteúdo, que, segundo Bardin é

Um conjunto de técnicas de análise das comunicações que, através de procedimentos sistemáticos e objetivos de descrição do conteúdo das mensagens, visa obter indicadores (quantitativos ou não) que permitam a inferência de conhecimentos relativos às condições de produção e de recepção (variáveis inferidas) destas mensagens (BARDIN, 2002, p. 46).

conteúdo expresso nos trabalhos constituíram três categorias: 1) características gerais da produção; 2) temáticas investigadas e referencial teórico; 3) caracterização metodológica (tipo, abordagem do problema, técnicas 
A formação de professores da educação profissional como objeto de estudo dos Programas de Pós-Graduação no Brasil

e instrumento de produção dos dados, lócus e sujeitos pesquisados, etc) conforme apresentamos a seguir.

\section{A formação de professores para o ensino técnico de nível médio nas produções acadêmicas}

\section{Características gerais das produções acadêmicas}

Analisando os dados do apêndice, identificamos o crescimento significativo de produções no período de 2010 a 2017 em relação à década anterior, pois a pesquisa de Pena (2011) havia identificado, no período de 2000 a 2009, apenas duas dissertações e Baptaglin (2013) identificou, no período de 1984 a 2011 , a existência de três teses.

Uma das razões dessa ampliação pode estar relacionada à expansão dos Institutos Federais de Educação após 2009, que passaram a contar com grande número de profissionais do magistério em processo de formação em nível de Pós-Graduação e elegeram a formação de professores da EP como

142 temática de investigação. Ainda, nesse sentido, há tendência à ampliação devido à criação de cursos de mestrado em EP, a exemplo do que ocorreu no Instituto Federal do Rio Grande do Norte.

o segundo aspecto analisado foi a distribuição espaço-temporal. Os dados indicam que, em relação ao tempo, ela foi praticamente uniforme, pois, em média, houve a elaboração de seis a oito trabalhos por ano, exceto em 2012. Quanto à dimensão espacial, a distribuição por região foi a seguinte: Sudeste - 21; Sul - 21; Nordeste - 9; Centro-Oeste - 5; Norte - 0.

Dois aspectos chamam a atenção nesses dados: a) a importância de criação do Programa de Mestrado em EP do IFRN que, em 2016, teve quatro produções na área; b) embora haja a tendência de interiorização das oportunidades educacionais, no tocante à Pós-Graduação continua havendo forte concentração de trabalhos nos estados de São Paulo (catorze), Rio Grande do Sul (treze) e Minas Gerais (oito) trabalhos.

Também identificamos as instituições de ensino superior onde os trabalhos foram produzidos, e concluímos que foram elaborados em trinta e três instituições: cinco na UNISINOS, quatro no IFRN, na UNB e na UFSC; três na 
UFRGS. Em nove instituições, foram produzidos dois trabalhos em cada uma e em dezenove, foi produzido um único trabalho.

Quanto à autoria, é acentuadamente feminina, pois 44 trabalhos foram produzidos por mulheres, e 12 por homens. $\bigcirc$ dado surpreende porque, embora o magistério seja considerado profissão feminina, na área técnica da EP, tem sido exercido, majoritariamente, por homens.

Em relação aos orientadores, os 56 trabalhos foram orientados por 49 diferentes pesquisadores e, somente, sete orientaram dois trabalhos e não pertencem à mesma instituição. Por outro lado, mesmo os trabalhos produzidos na mesma instituição, exceto o IFRN, estão vinculados a diferentes Programas de Pós-Graduação, o que indica a quase inexistência de grupos regionalizados de pesquisa sobre EP.

Constatamos, ainda, a ausência de pesquisas sobre formação de professores para a EP, orientadas por pesquisadores citados nas pesquisas como referenciais da área, como Lucília Machado, Gaudêncio Frigotto, Maria Ciavatta, Marise Ramos, Ronaldo Araújo, entre outros.

Consultando o currículo lattes desses pesquisadores, confirmamos que não tem orientado pesquisas nessa área. Usando o mesmo recurso, categorizamos a produção acadêmica dos orientadores dos trabalhos analisados em três grupos: o primeiro, formado por vinte e três pesquisadores, dedica-se à pesquisa de temas como "formação de professores", "didática", "currículo", "avaliação"; o segundo grupo, constituído por quinze pesquisadores, escreve sobre temas ligados à EP; por fim, o terceiro grupo, com onze pesquisadores, trata de temas diversos relativos às suas áreas de formação. A partir de 2013, vários orientadores dos grupos um e dois passaram a escrever sobre formação de professores da EP, alguns em parceria com seus orientandos.

\section{Temáticas investigadas e referencial teórico adotado}

A leitura dos trabalhos permitiu organizar as temáticas investigadas em cinco categorias (conforme consta na Tabela 1). 
A formação de professores da educação profissional como objeto de estudo dos Programas de Pós-Graduação no Brasil

\section{Tabela 1}

Temáticas das teses e dissertações sobre formação de professores para a educação profissional - 2010 a 2017

\begin{tabular}{|c|c|c|c|}
\hline Temáticas & Trabalhos/autor & $\mathrm{N}^{\circ}$ & $\%$ \\
\hline $\begin{array}{l}\text { A) Constituição da } \\
\text { docência/saberes } \\
\text { docentes na EP }\end{array}$ & 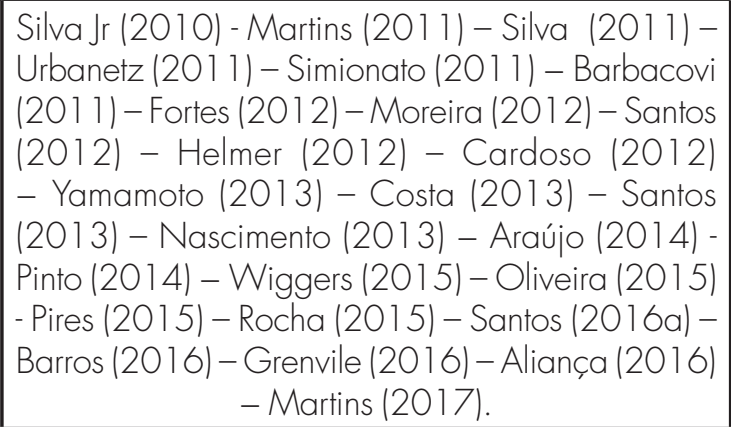 & 26 & 46,5 \\
\hline $\begin{array}{l}\text { B) Políiticas de forma- } \\
\text { ção de professores } \\
\text { para a EP }\end{array}$ & 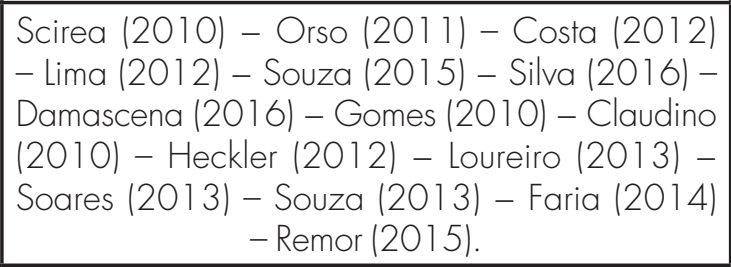 & 15 & 26,7 \\
\hline $\begin{array}{l}\text { C) O professor da } \\
\text { EP: razões do in- } \\
\text { gresso na docência, } \\
\text { perfil, identidade e } \\
\quad \text { trajetória. }\end{array}$ & $\begin{array}{l}\text { Mascarello (2010) - Ferreira (2010) - Vieira } \\
(2010) \text { - Milanelli (2010) - Pereira (2012) - } \\
\text { Fernandes (2012) - Brito (2012) - Frozoni (2013) } \\
\text { - Silva (2014) - Silva (2015) - Santos (2016). }\end{array}$ & 11 & 19,6 \\
\hline $\begin{array}{l}\text { D) Conhecimento } \\
\text { pedagógico do } \\
\text { conteúdo dos profes- } \\
\text { sores da EP }\end{array}$ & Souza (2013) - Pena (2014) - Santos (2015). & 3 & 5,4 \\
\hline $\begin{array}{c}\text { E) } \begin{array}{c}\text { Pesquisa sobre } \\
\text { pesquisas }\end{array} \\
\text { pas }\end{array}$ & Oliveira (2016). & 1 & 1,8 \\
\hline
\end{tabular}

Fonte: produzido pelos autores com base nos trabalhos localizados no banco de teses e dissertações da Capes, no IBICT e sites dos Programas de Pós-Graduação.

Organizada em ordem decrescente, a Tabela 1 permite visualizar que, no período analisado, o foco das produções foi a discussão sobre a constituição profissional, os saberes docentes, as políticas de formação de professores e perfil dos profissionais da área. Há trabalhos que tratam das várias 
temáticas elencadas, porém a classificação considerou o objetivo de pesquisa anunciado.

Em relação à base teórica ou autores que subsidiaram as reflexões propostas, em várias produções, as informações não constam nas seções analisadas. Essa lacuna poderia ser suprida analisando a íntegra do trabalho e as referências, porém, dado ao grande número de autores citados, poderíamos incorrer no erro de considerar como fundantes trabalhos que não foram centrais no estudo e, por isso, não os citamos. Omitimos na autoria, o ano da publicação da obra, já que esses autores não estiveram presentes em todos os resumos e consideramos que a inclusão desse dado não acrescenta informação relevante ao estudo e dificulta a leitura.

\section{A) Constituição da docência/saberes docentes na EP}

Nessa categoria, incluímos vinte e seis trabalhos, que analisaram como os professores da EP se constituem docentes. Partindo do pressuposto referendado em experiências profissionais na área e resultados de pesquisas anteriores - que a maioria dos profissionais da EP não tem formação pedagógica, os autores procuram desvelar como esses profissionais desenvolvem os saberes requeridos pela profissão docente.

Wiggers (2015) analisou como os professores aposentados, na EP, se constituíram docentes no período de 1968 a 2010 e concluiu que foram fatores relevantes: a frequência a formação continuada; as relações estabelecidas com profissionais da área pedagógica e os processos de construção coletiva envolvidos com essa área; o aprendizado advindo das interações com os pares; a experiência profissional, as pesquisas de campo, atividades fora das salas de aula e nos cargos de gestão.

Quanto às vinte e cinco pesquisas restantes, optamos por sintetizar os principais achados, indicando os autores que apontam fatores que influenciaram a constituição da docência dos professores da EP:

a) A construção de conhecimentos sobre e para a docência ocorreu por meio da prática vivenciada em sala de aula - foi o fator recorrente em 18 trabaIhos: Urbanetz (201 1), Barbacovi (201 1), Silva (201 1), Martins (201 1), Silva Jr (201 1), Fortes (2012), Santos (201 2), Cardoso (2012), Helmer (2012), Moreira 
A formação de professores da educação profissional como objeto de estudo dos Programas de Pós-Graduação no Brasil

(2012), Yamamoto (2013), Costa (2013), Nascimento (2013), Santos (2013), Pires (2015), Oliveira (2015), Santos (2016), Aliança (2016).

b) Por meio do conhecimento tácito, adquirido nas vivências do campo profissional de formação inicial, apontado em quinze trabalhos: Martins (2011), Simionato (201 1), Silva Jr (201 1), Santos (2012), Fortes (2012), Helmer (2012), Yamamoto (2013), Costa (2013), Pinto (2014), Santos (2013), Nascimento (2013), Araújo (2014), Pires (2015), Rocha (2015) e Aliança (2016).

c) A contribuição dos pares no processo de formação para a docência foi um fator relevante apontado por doze autores: Urbanetz (201 1), Silva (201 1), Martins (201 1), Simionato (201 1), Silva Jr (201 1), Fortes (2012), Moreira (2012), Santos (2013), Pires (2015), Pinto (2014), Grenvile (2016) e Aliança (2016). A troca de experiências com os colegas de trabalho pôde ajudar no trabalho docente, pois os diálogos que travaram com os outros thes permitiram conhecer outras experiências e pontos de vistas.

d) Eventos de formação continuada foram relevantes em oito pesquisas: Urbanetz (201 1), Barbacovi (20 1 1), Silva (201 1), Martins (201 1), Yamamoto (2013), Pinto (2014), Nascimento (2013) e Santos (2013).

146 e) A experiência como aluno e a influência dos professores referenciais na formação repercute na constituição da docência, pois os docentes tendem a repetir os modelos dos "bons professores" - fator presente em doze trabalhos: Urbanetz (201 1), Martins (20 1 1), Fortes (2012), Cardoso (2012), Yamamoto (2013), Oliveira (2015), Moreira (2012), Nascimento (2013), Santos, E. (2013), Rocha (2015), Santos, T (2016) e Aliança (2016). Na EP, essa relação é acentuada porque, na ausência de formação para a docência, o professor baseia sua prática nas ações que vivenciou como estudante, reproduzindo o modelo dos seus docentes.

f) Aprendizados adquiridos na "cultura institucional", que o professor vivencia (participação em reuniões, conselho de classe, eventos, etc.), foram citados em cinco trabalhos: Martins (201 1), Fortes (2012), Simionato (2011), Pires (2015) e Grenvile (2016). Pires (2015) analisou a influência da cultura institucional na constituição de docentes e constatou que a forma de organização física e curricular das escolas tem ocasionado o isolamento docente e a balcanização, e que há poucos indícios que incentivem o desenvolvimento de uma cultura de colaboração entre os docentes e classificou, como "colegialidade artificial", as relações que os professores estabelecem entre si. 
g) Por meio das experiências trocadas com os discentes, fator citado por Silva (201 1), Santos (2013) e Pires (2015). Os pesquisados indicam que o contato com os estudantes se torna formativo por permitir a interação com a realidade escolar, a revisão de conceitos, a busca de novas estratégias de ensino e de ałuação em função das situações vivenciadas.

Buscamos, nas vinte e seis pesquisas desse grupo, identificar o papel atribuído à formação pedagógica na constituição docente e em cinco (FORTES, 2012; SANTOS, 2012 ; PINTO,20 14; ROCHA, 2015; ALIANCCA, 20 16) não localizamos evidências para concluir a posição dos pesquisados. Nas demais, há duas posições: conclusões que reforçam a necessidade e importância dessa formação e outros estudos que a consideram dispensável.

No primeiro grupo, estão onze estudos, conforme transcrições a seguir:

a) Wiggers (2015) identificou a importância atribuída aos cursos de formação para a docência, mesmo que de curta duração.

b) Santos (2013, p. 139) concluiu que foi quase unânime entre os entrevistados o reconhecimento de que a formação pedagógica "[... ] constitui aporte importante para o exercício da docência no ensino técnico-profissional. Essa posição parece retificar a consciência de que a ausência dessa formação pode gerar impactos ao ofício de ensinar".

c) Simionato (2011) pesquisou candidatos ao ingresso em um Programa de Formação Pedagógica e constatou que esses valorizam essa formação, porém ainda não se identificavam como professores.

d) Urbanetz (201 1 ) constatou que os professores que fizeram a formação pedagógica (Esquema I ou II) indicaram que o curso acrescentou pouca melhoria em sua atuação docente, porém, dos onze que cursaram especialização lato sensu na área pedagógica, oito consideram que ela contribuiu com a melhoria de sua atividade docente, e três afirmam que não perceberam melhoria expressiva.

e) Martins (2011, p. 121) concluiu que as professoras "[...] consideram a necessidade e importância de uma qualificação na área educacional, além de indicarem enfaticamente a preocupação e o comprometimento com a aprendizagem dos alunos". 
A formação de professores da educação profissional como objeto de estudo dos Programas de Pós-Graduação no Brasil

f) Cardoso (2012, p. 104) concluiu que "[...] os conhecimentos pedagógicos adquiridos nos cursos de formação para a docência, concluídos ou ainda em andamento, também são apontados como elementos do processo de aprendizagem da profissão".

g) Yamamoto (2013, p. 107) pesquisou professores que haviam participado de um programa de formação continuada para a docência e concluiu que eles avaliaram o programa "[...] de forma positiva, inclusive, como o primeiro contato que tiveram com temas educacionais, além de trazer reflexões significativas de mudança de paradigmas dos professores".

h) Pires (2015, p. 180) afirma que os pesquisados reconhecem que o curso de formação para a docência contribuiu com "[...] conhecimentos sobre o ensino, a aprendizagem e a própria postura docente, fortalecendo, assim, a necessidade de investimentos na formação dos professores nessa modalidade de ensino".

i) Por fim, três estudos - Barros (2016), Granvile (2016) e Souza (2017) reportam que a maioria dos pesquisados reconhece a necessidade e a contribuição da formação pedagógica para melhor compreensão, domínio e atuação na docência.

No segundo grupo, estão inclusas dez pesquisas que apontaram pouca importância atribuída à formação pedagógica para a docência:

a) Silva (201 1, p. 155) afirma que os pesquisados, "[...] embora acreditem que as licenciaturas dão suporte a vários conhecimentos necessários para a prática docente, não consideram a ausência dessa formação um impeditivo para atuarem como professor".

b) Silva Jr (201 1, p. 16) constatou que "esse tipo de formação, apesar de ser um ponto lacunar na formação desses professores, constitui elemento pouco potente ou relevante para o processo de constituição de sua identidade docente".

c) Moreira (2012) concluiu que os conhecimentos didático-pedagógicos e as contribuições advindas da área de educação são minimizadas ou desvalorizadas pela maioria dos docentes entrevistados.

d) Barbacovi (2011) comenta que os pesquisados atribuem pouca importância à formação inicial ou continuada na área da docência. 
e) Helmer (2012) reporta que poucos entrevistados apontaram a necessidade de formação pedagógica como possibilidade de enriquecimento da atuação; f) Costa (2013) concluiu que os professores que possuem formação técnica, embora reconheçam suas limitações para compreender os aspectos pedagógicos da docência, não demonstraram interesse em participar de programas de formação pedagógica.

g) Nascimento (2013) identificou que a formação inicial em curso de formação para o magistério foi importante apenas para um dos sete pesquisados, e a formação continuada foi pouco frequente nas respostas.

h) Oliveira (2015) constatou que a totalidade dos bacharéis investigados não considera a formação pedagógica essencial para a atuação docente, reduzindo-a à aprendizagem de métodos e técnicas de ensino e, embora a considerem importante para o aprimoramento da prática educativa, demonstram pouco interesse em estudos sobre as Ciências da Educação.

i) Araúio (2014, p. 174) concluiu que a formação inicial dos professores investigados foi calcada "[...] em base positivista que afasta qualquer possibilidade de uma contribuição no campo da formação pedagógica (ciência da educação)" e que "[...] A profissão docente na EPT se mostra fragilizada em um horizonte que caminha para o enraizamento da cultura de que não é necessária a formação pedagógica para exercer a docência e, assim, onde todos podem exercer essa atividade" (ARAÚJO, 2014, p. 174).

i) Santos (2016a) concluiu que os pesquisados desvalorizam os conhecimentos pedagógicos, pois os que cursaram formação pedagógica o fizeram por exigência do edital de seleção e os que ingressaram sem esse requisito não manifestaram interesse em realizar o curso.

No que tange à abordagem teórica, Santos (2016, p. 16) a identifica como fenomenológica e três autores explicitam, textualmente, o materialismo histórico dialético como referência: Urbanetz (2011), Simionato (201 1) e Pinto (2014). A primeira não nomeia os autores fundantes da pesquisa, mas relata que o trabalho está "[...] apoiado na revisão da literatura de autores clássicos e especialistas da área". Simionato (2011) informa que a análise da cultura docente foi realizada a partir da ótica de Hargreaves, Pérez Gómez, Garcia e Imbernón. $O$ estudo de Pinto (2014) teve como referenciais: Gramsci, Freire, Machado, Tardif, Cunha, Kuenzer e Manfredi. 
A formação de professores da educação profissional como objeto de estudo dos Programas de Pós-Graduação no Brasil

Em três pesquisas, não há identificação da linha teórica, mas indicam as referências: Silva Júnior (2010) se valeu dos aportes teóricos da epistemologia da prática docente; Santos (2012) se inspirou na metáfora do rizoma de Deleuze, nas três ecologias de Guattari e nas perspectivas de ética de Spinoza, Morin e Maturana e Varela, e Grenvile (2016) indica que utilizou o referencial de Tardif. Em dezessete pesquisas, não há identificação de linha teórica, mas, no resumo, constam os autores referenciais. Por fim, as pesquisas de Helmer (2012) e de Rocha (2015) não apresentam, no resumo ou introdução, a linha teórica, tampouco indicam os principais autores pesquisados.

\section{B) Políticas de formação de professores para a EP}

Quinze trabalhos tiveram por escopo analisar as políticas de formação de professores para a EP técnica de nível médio, sendo que sete foram produzidos por meio da análise de leis, decretos e pareceres referentes ao tema, e oito trabalhos trataram das políticas de formação de professores para a EP, apresentando experiências de oferta de cursos de licenciatura ou Programas de Formação de Docentes para a EP.

$150 \quad$ No primeiro grupo, estão os trabalhos de Scirea (2010), Orso (2011), Lima (2012), Costa (2012), Souza (2015), Silva (2016) e Damascena (2016) que apontam que, na última década, as políticas educacionais revelam esforços para superar a dualidade estrutural por meio do ensino médio integrado à formação profissional, porém as instituições ainda são deficientes nos investimentos em estrutura física e qualificação dos docentes.

Em relação à formação de professores da EP, os trabalhos, de modo geral, concluem que não houve avanços significativos, já que as legislações que regulamentam essas políticas são pontuais, insuficientes e fragmentadas. Destacam, como exemplo, os programas especiais de formação docente para a EPT, que caracterizam como medida paliativa de cunho imediatista, reducionista e aligeirada. Entretanto, Costa (2012) e Souza (2015) informam que, nas instituições pesquisadas há a valorização dessa formação, pois vem sendo criada política institucional que exige licenciatura ou programa de formação pedagógica como requisito para a contratação de docentes.

Costa (2012) destaca que os IFEs têm se dedicado mais em habilitar professores para a educação básica do que cursos de formação para a docência na EP. Essa situação é ratificada por Lima (2012), que pesquisou os 
IFEs como lócus de formação de professores e concluiu que a primazia é para a oferta de licenciaturas para a educação básica, enquanto a formação de professores para a EP é ofertada de forma inexpressiva, o que permite inferir que a missão dos IFEs como lócus de formação docente para a EP não está sendo cumprida.

Quanto à base teórica, as pesquisas fundamentam-se no materialismo histórico e utilizam textos de autores que analisam, criticamente, as relações entre o trabalho e a educação na sociedade capitalista.

No segundo grupo, estão oito trabalhos sobre políticas de formação de professores para a EP, apresentando: I) experiências de oferta de cursos de licenciatura (FARIA, 2014; LOUREIRO, 2013; SOUZA, 2013); II) Programas de Formação de Docentes para a educação técnica e tecnológica (GOMES, 2010 ; CLAUDINO, 2010; HECKLER, 2012; SOARES, 2013; REMOR, 2015). Os trabalhos do subgrupo II verificaram se e como os programas contribuíram para a formação e o trabalho docente, enquanto os do subgrupo I abordaram o processo de formação e condições de trabalho dos formadores que atuavam nos cursos analisados. Quanto ao lócus das pesquisas, os programas pesquisados foram os ofertados pelo Centro Paula Souza - SP, UTFPR (2 trabalhos), IFMG (2 trabalhos), e um num IF do RS.

As conclusões dos trabalhos que pesquisaram os programas de formação pedagógica foram diferenciadas. Segundo Gomes (2010), Soares (2013) e Remor (2015), os programas analisados contribuíram para a formação pedagógica dos cursistas, como expressam nos excertos a seguir:

[... foi possível perceber o "pré-conceito" existente por parte desses professores em relação à Pedagogia antes da realização da licenciatura, entretanto, ao fazê-la, todos perceberam mudanças em suas práticas docentes. Foi possível perceber, também, que os cursos oferecidos ainda estão aquém do que poderiam ser, embora denotem significado para esses professores, pois todos puderam perceber a importância desta formação em suas carreiras, o que derruba o senso comum em acreditar que o caráter pedagógico para estes professores é inexistente (GOMES, 2010, p. 106, grifos nossos).

[...] avalia-se que o Programa Especial de Formação Pedagógica é comprometido com uma formação consistente, levando em consideração as particularidades de seus alunos, que são oriundos 
A formação de professores da educação profissional como objeto de estudo dos Programas de Pós-Graduação no Brasil

de cursos que não contemplam formação didático-pedagógica (SOARES, 2013, p. 10, grifos nossos).

[...] concluímos que o Profop UTFPR - Câmpus Medianeira - apresenta-se como importante iniciativa na formação de professores para suprir a demanda por docentes na Educação Básica, Educação Profissional Técnica de Nível Médio e EPT (REMOR, 2015, p. 108, grifos nossos).

Em sentido contrário, Claudino concluiu que o programa analisado não atingiu os objetivos propostos, pois,

[...] carece de definições em sua concepção e de adequações em sua estrutura, na forma de oferta e especialmente de entrosamento entre os envolvidos, a fim de que alguns entraves sejam superados e que os objetivos sejam atingidos, não se limitando a certificação de licenciatura. [...] o referido programa não atende às necessidades de formação de docentes para atuar na educação profissional e tecnológica adequada à formação humana integral (CLAUDINO, 2010, p. 126, grifos nossos).

Outras pesquisas que abordaram o tema foram a de Heckler (2012) 152 e Souza (2013). A primeira tratou da docência no PROEJA num IFE e comentou sobre a participação dos professores num curso de especialização para a docência em PROEJA, concluindo que houve diminuta adesão ao curso oferecido pela instituição e, entre os professores mais resistentes ao programa, citou os das áreas técnicas. Já Souza (2013) pesquisou as políticas de formação de professores de um IFE para problematizar o dilema da EPT entre formação integral e formação para o mercado, na perspectiva da Educação Ambiental e conclui pela defesa dos IFEs como lócus de formação de professores para a EP.

Faria (2014) teve, como propósito, identificar a formação, o trabalho e as condições salariais dos professores que ministram aulas num Programa Especial de Formação Pedagógica de Docentes. Concluiu que eles possuem elevado nível de formação acadêmica; estão, em sua maioria, satisfeitos quanto à questão salarial; possuem autonomia na prática docente e boa convivência no ambiente organizacional e que há satisfação no exercício da profissão, elemento importante e necessário para o "fazer" docente.

Loureiro (2013) objetivou compreender como ocorreu a formação de formadores enquanto formavam docentes para atuar na EP no curso de 
Marilandi Maria Mascarello Vieira | Josimar de Aparecido Vieira | Maria Cristina Pansera de Araújo 듬

licenciatura. Aponta que essa formação ocorreu na prática por meio de Roda dos Formadores (WARSCHAUER, 2001), em uma Comunidade Aprendente (Brandão, 2005) que rompe com os modelos tradicionais e defende a formação docente na prática, desde que o conhecimento que a conduza seja construído coletivamente com a reflexão das experiências vivenciadas e escritas pelos membros da comunidade.

No que concerne à base teórica, não estão explicitadas nos trabaIhos, somente foram incluídos nos resumos as obras citadas.

C) $\bigcirc$ professor da EP: razões do ingresso na docência, perfil, identidade e trajetória

Nesse grupo, incluímos onze trabalhos que caracterizaram os professores da EP em relação às razões para a escolha profissional, perfil e trajetórias de formação e processo de construção da identidade docente.

Mascarello (2010) objetivou compreender o que leva profissionais de distintas formações a se interessar pelo trabalho docente na EP e concluiu que as razões são de duas dimensões: histórica e ontológica, ou seja, o trabalho enquanto necessidade e o trabalho enquanto liberdade. Essas dimensões são responsáveis pelo (re) direcionamento de carreira, pois eles percebem que a docência thes confere elevação de status em relação às suas profissões de origem e contribui para a melhoria de vida dos alunos.

Traçar o perfil e a trajetória de formação dos professores da EP foi o objetivo de Vieira (2010) e Silva (2015), que concluem que aqueles professores têm boa titulação e produção intelectual; escolheram a docência de forma não planejada, mas contingencial; não tiveram formação para a docência e, embora reconheçam essa carência, não investem nela de forma sistemática. Para o exercício da docência, tomam, como referência, seus professores, interagem com pares mais experientes; estão atentos às demandas dos alunos e investem tempo na elaboração das aulas e, de modo geral, demonstram estar realizados pessoal e profissionalmente. Vieira (2010) verificou se os professores estabelecem relação entre o que ministram e os arranjos produtivos locais e concluiu que eles incorporam o espírito da EP e a formação direcionada ao mercado, pois tentam adequar seu trabalho às demandas produtivas de especialização do conhecimento. 
A formação de professores da educação profissional como objeto de estudo dos Programas de Pós-Graduação no Brasil

Os trabalhos de Ferreira (2010), Milanelli (2010), Pereira (2012), Fernandes (2012), Frazoni (2013), Silva (2014) e Santos (2016a) têm em comum a centralidade na construção da identidade docente pelos professores que atuam na EP. Ferreira (2010) focou-se em três aspectos: a) relação entre atuação e identificação docente, b) relação entre formação e prática, e c) sentimento de pertença ao grupo. Concluiu que os professores continuam a ser recrutados no mundo do trabalho, iniciam a docência sem formação pedagógica e a formação em serviço não acontece ou não contribui para a formação da identidade docente, que é construída a partir da ressignificação das vivências da escola e do mundo do trabalho.

Pereira (2012) se propôs a investigar as representações sociais dos professores sobre a identidade docente, os elementos que a constituem e as implicações desse processo identitário e representativo para a EP e concluiu pela existência de elementos que apontam para um jogo de influências exercidas de um lado, pela instituição; e de outro, pelos professores e entre eles, o que culmina em uma imagem profissional. Há conflito entre expectativas profissionais e demandas institucionais, gerando desconforto profissional, discurso ambivalente e fragmentação do grupo. Assim, os elementos identificados dão

154 sentido e levam à compreensão dessas representações sociais dos professores sobre sua constituição identitária. Daí, decorrem implicações para a escola de EP que remetem à concepção de identidade profissional docente ainda indeterminada.

As pesquisas de Milanelli (2010) e de Frazoni (2013) foram realizadas com enfermeiros professores que atuam na docência e, ao mesmo tempo, na profissão de origem e, por isso, oscilam entre a identidade das duas profissões. Os dados apontaram a existência de sentimentos prazerosos e frustrantes em relação à docência, dificuldades e desafios enfrentados na carreira, relação com a formação pedagógica e com a construção de conhecimentos e concluíram que os profissionais pesquisados estão satisfeitos com a atividade docente, que também gostam da profissão de origem, mas frustrados com as condições de trabalho e desejando ter mais tempo para se dedicar às atividades docentes.

Silva (2014) questionou como se pode construir identidade docente, capaz de articular a formação dos alunos para o mundo do trabalho e para a vida e concluiu que a identidade profissional dos professores é forjada nos processos de sua formação e de socialização profissional. Desse modo, a 
Marilandi Maria Mascarello Vieira | Josimar de Aparecido Vieira | Maria Cristina Pansera de Araújo 듬

identidade profissional dos professores da EPTNM é construída por meio da formação e das atividades próprias do seu ofício e dos papéis exercidos na sua profissão, concluindo, assim, que a sua identidade profissional é voltada aos interesses do mercado. Defende a necessidade de superar essa lógica de modo que os professores comprometam-se com a emancipação plena do sujeito e isso não se efetiva somente através da formação de professores, mas também por políticas educacionais com pautas que produzam uma nova práxis.

Santos (2016a) concluiu que a construção da identidade docente se dá nos espaços e dinâmicas da profissão docente (descoberta de ser EBTT), os institucionais (na angústia de entender o IFE) e os de subjetividade e de afeto (de ter o futuro incerto). Por fim, Fernandes (2012, p. 8) analisou os processos identitários docentes de professores que lecionam no PROEJA de um IF visando compreender como têm sido constituídas as suas identidades de professores e que papel a experiência exerce nesse sentido. Concluiu que esse processo é permeado pela reflexão sobre o ato de ensinar a pessoas jovens e adultas, "[...] caracterizado por um jogo de identificação entre as identidades para outro, atribuídas pelos sistemas peritos - ser professor de EJA - e a identidade para si - ser professor da educação profissional".

Brito (2012) pesquisou a formação e as condições de trabalho dos docentes que atuam na Educação de Jovens e Adultos, num IF e concluiu que a oferta de cursos técnicos pelo PROEJA ocorreu sem a existência de uma política de formação continuada destinada aos professores da instituição. Embora esta tenha ofertado curso de especialização em educação de jovens e adultos integrada à EP, o mesmo não foi prioridade dos professores do quadro efetivo, o que dificultou o exercício da docência especialmente por parte dos professores das áreas técnicas.

Analisando as bases teóricas das pesquisas, Pereira (2012) menciona a Teoria das Representações Sociais - TRS, e em relação à constituição da identidade profissional, dialoga com Dubar, Nóvoa, Contreras, Abdalla e Tardif, entre outros. Já Silva (2014) tomou como referência o método dialético e as produções de Ciavatta, Ramos, Frigotto, Grabowski, Kuenzer, Manfredi, Machado, Oliveira, Evangelista e Shiroma e Mészáros. Os demais autores não expressam a linha teórica, mas, no resumo, indicam as principais referências. No resumo e introdução dos trabalhos de Vieira (2010) e Silva (2015) não consta essa informação. 
A formação de professores da educação profissional como objeto de estudo dos Programas de Pós-Graduação no Brasil

D) Conhecimento pedagógico do conteúdo dos professores da EP

Essa temática está ligada à constituição da docência na EP, mas optamos por distingui-la nessa análise por se tratar de tema pouco difundido nos trabalhos, já que somente Souza (2013), Pena (2014) e Santos (2015) tomaram Shulman como referência. $O$ primeiro e o terceiro foram realizados no Programa de Pós-Graduação em Enfermagem da UFSC com professores de cursos técnicos em enfermagem, enquanto o segundo foi desenvolvido no Programa de Pós-Graduação em Educação da UFMG com professores que atuam em cursos técnicos de nível médio no IFMG - Câmpus Ouro Preto. A base teórica foi Shulman (1986), e Pena (2014) incluiu Chevallard (1998).

O objetivo de Souza (2013) foi compreender como o enfermeiro desenvolve o preparo pedagógico para docência à luz do Conhecimento Pedagógico do Conteúdo de Shulman. A análise de dados recaiu sobre as categorias de Shulman: conhecimento do conteúdo, conhecimento pedagógico geral, conhecimento do currículo, conhecimento do contexto educacional. Ademais, enfocou, como fontes de constituição da docência, a relação com os pares, a formação pedagógica e as experiências vivenciadas como aluno.

156 Por fim, apontou as dificuldades enfrentadas pelos professores enfermeiros na docência. Assim, embora o título do trabalho e o objetivo indiquem a centralidade na categoria "conhecimento pedagógico do conteúdo" o trabalho de fato não aprofundou o estudo dessa categoria.

Segundo Santos (2015), o objetivo do trabalho foi compreender como é constituído o conhecimento pedagógico do conteúdo (CPC) de professores intermediário e experimentado no exercício da docência na EP de Nível Técnico em Enfermagem. No referencial teórico, aborda as contribuições de Shulman para o ensino, enfocando o modelo de ação e raciocínio pedagógico e as bases para o ensino, em que situa o conhecimento pedagógico do conteúdo, porém não há aprofundamento dessa categoria. A análise de dados está centrada, especialmente, no processo de construção e fontes do CPC, Mentoring como fonte para a construção do CPC e expressão do CPC no modelo de raciocínio e ação pedagógicos, na trajetória de formação daqueles profissionais.

A tese de Pena (2014) investiga a docência na EP considerando as suas especificidades e teve como objetivo identificar e analisar as estratégias de didatização e o conhecimento pedagógico do conteúdo na prática docente 
de professores de disciplinas técnicas. A tese traça breve panorama sobre as pesquisas acerca do ensino, enfoca em Shulman os conhecimentos de base, o CPC e, também, a transposição didática de Chevallard (1998). Segundo Pena, os resultados apontam para as especificidades da docência nessa modalidade de ensino e, na ausência da formação pedagógica, os professores desenvolvem sua prática por meio de diferentes estratégias de didatização. Destacou como fontes de conhecimentos para o ensino em distintas situações vivenciadas na trajetória acadêmica, no exercício profissional como docente e a profissão de origem e por meio da busca pessoal pelo desenvolvimento profissional.

Por fim, Oliveira (2016) mapeou as produções bibliográficas sobre a formação de professores para a EP (2004 a 2014) analisando quarenta e quatro produções: seis trabalhos em eventos; seis artigos em periódicos; dez teses e vinte e quatro dissertações.

Concluído o inventário das produções acadêmicas, destacamos alguns aspectos quanto às temáticas. Os trabalhos anteriores a 2010 davam ênfase à retrospectiva história da EP e nos trabalhos analisados, essa temática, embora não se constitua no foco central, é recorrente, em alguns de forma mais completa enquanto em outros o recorte é mais preciso. Também comum é a análise das políticas de formação de professores, variando apenas a profundidade com que é tratada. A terceira temática constante é o estado do conhecimento referente aos temas das investigações, que consta em catorze pesquisas, com variações no período de abrangência (1987 a 2009, em sua maioria) e de fontes consultadas (revistas, eventos, portais de consulta de teses e dissertações). Um ponto comum é a constatação da existência de poucas teses e dissertações sobre o tema até 2010 e um acréscimo expressivo a partir de então.

Os estudos analisados traçam o perfil dos professores que atuam na EP indicando as razões para o ingresso na docência, trajetórias de formação e de construção de identidade. Mesmo nos trabalhos orientados por outros objetivos, essas temáticas estão presentes. Predominam os estudos acerca da constituição da docência e os saberes requeridos dos professores da EP, objeto de $46,5 \%$ dos estudos.

Quanto à base teórica, está explícita, apenas, em algumas teses e ausente na maioria dos trabalhos dissertativos. Embora seja uma tarefa difícil classificar os autores citados pelos pesquisadores, grosso modo podemos 
A formação de professores da educação profissional como objeto de estudo dos Programas de Pós-Graduação no Brasil

apontar três grupos: os que pesquisam sobre EP no Brasil (como Frigotto, Kuenzer, Machado, Ciavatta, Ramos, entre outros); os que têm por foco a construção da identidade, especialmente Dubar e Hall, e os que tratam do professor crítico-reflexivo e dos saberes docentes, considerados bases para o ensino, como Schon, Nóvoa, Huberman, Tardif, Gauthier, Shulman, entre outros. Constatamos a forte influência de Tardif como referência sobre constituição da docência e consta nas referências de muitos trabalhos.

Na próxima seção, tratamos do percurso metodológico, enfocando o tipo, procedimentos adotados, sujeitos das pesquisas e lócus dos trabalhos.

\section{Percurso metodológico}

Em relação à abordagem da pesquisa, quarenta e dois autores a identificam como qualitativa, quatro como quanti-qualitativa e dez não fazem referência à abordagem. Já referente às técnicas de pesquisa, em vinte e cinco estudos não consta essa informação e nas demais (trinta e uma) o estudo de caso prevalece em vinte pesquisas, dez foram classificados como autobiográficos, duas como etnográficas, uma é pesquisa-ação e outra pesquisa formação.

Quanto aos procedimentos adotados, a maioria das pesquisas (trinta e sete) é de campo e as restantes combinam dois ou mais procedimentos: seis são bibliográficas e documental; dez são documentais e de campo e três combinam os três procedimentos. Consideramos relevante que as pesquisas sejam predominantemente de campo, pois, mesmo que sejam majoritariamente estudos de caso, há preocupação em ouvir os protagonistas do processo, ou seja, os professores que atuam na EP.

Os instrumentos mais usuais na pesquisa de campo foram a entrevista (trinta e nove); questionário (vinte); observação (dez), grupo focal (quatro); produção de narrativas escritas (três) e realização de oficinas pedagógicas (uma). Das cinquenta pesquisas de campo, vinte e seis utilizaram dois ou mais instrumentos de coleta de dados.

Por se tratar de estudos referentes à formação de professores, eles são os principais sujeitos investigados em quarenta e oito das cinquenta pesquisas de campo. Em algumas, há a participação dos alunos e demais profissionais do magistério (reitores e coordenadores de curso). Prevalecem pesquisas com baixo número de sujeitos, principalmente quando se faz uso da entrevista e da 
observação, caso em que foram investigados até cinco professores (dez ocorrências), de seis a dez professores (vinte ocorrências) e mais de dez sujeitos (quinze ocorrências), sendo que três não informam o número de professores pesquisados. Quando há o uso de questionários a tendência é de inclusão de questões fechadas cujos dados podem ser quantificados e há a ampliação do número de investigados.

Em relação ao lócus, nos trabalhos em que foi possível identificá-lo, a maioria (trinta e cinco) foi realizada nos IFEs, seis estudos em Programas de Formação Pedagógica de IES públicas ou privadas e nove em escolas técnicas estaduais de nível médio, privadas ou pertencentes ao Sistema S.

Quanto aos pesquisadores, no caso de pesquisa de campo, em 36 os dados foram produzidos nas instituições onde os autores trabalham e sobre temas dos seus universos de atuação, o que demonstra vínculo entre a pesquisa e a prática profissional dos professores, que Diniz-Pereira (2010, p. 84) chama de epistemologia da experiência, que conceitua como "[...] o estudo dos conhecimentos e saberes sobre a docência produzidos por meio da(s) experiência(s) dos professores ou, melhor dizendo, das reflexões individuais e/ ou coletivas que estes fazem sobre sua(s) experiência(s)".

Constatamos ausência de informações relevantes acerca do percurso metodológico adotado na produção do estudo, notadamente nas dissertações. Nas pesquisas documentais e bibliográficas, não há indicativos da base teórica sobre a qual se assentou a análise, ou seja, a partir de que parâmetros o autor interpreta os documentos e literatura sobre o tema.

\section{Considerações finais}

Como conclusão da análise, apontamos acentuada ampliação dos estudos a partir de 2010. A produção - considerando que o tempo para realização de dissertações é, em média, dois anos e as teses quatro anos - teve início de 2008 até 2017 e tiveram como lócus, em sua maioria, os IFEs, instituições que buscam construir sua identidade institucional e isso se reflete nas pesquisas que versam sobre o perfil, trajetória de formação e construção de identidade docente, temáticas presentes na maioria dos trabalhos. Por se tratar de tema novo, as pesquisas se centram mais em informações descritivas do que propriamente explicativas. 
A formação de professores da educação profissional como objeto de estudo dos Programas de Pós-Graduação no Brasil

Quanto ao lócus de formação dos professores da EP, prevalecem os Programas de Formação Pedagógica de Docentes e somente dois trabalhos referenciaram cursos de especialização lato sensu, o que indica que eles não têm sido alternativa para a formação desses profissionais. $\bigcirc$ mesmo se pode afirmar em relação às licenciaturas destinadas à formação dos professores das áreas técnicas, pois, embora a legislação que criou os IFEs tenha previsto essa oferta como uma de suas funções, o tema está praticamente ausente das pesquisas.

A constituição das bases de conhecimentos para o ensino também é tema de debates e podemos destacar como singularidade da docência na EP a ausência de formação pedagógica, confirmando o que apontam estudos anteriores. Na ausência dessa formação, as fontes de conhecimento para a elaboração dos saberes é, sobretudo a prática, quer advinda do exercício da docência, quer da prática como profissional na área técnica. Nesse sentido a categorização dos saberes de Tardif e colaboradores, Gauthier; Martineau; Desbiens; Malo; Simard, além de autores nacionais como Pimenta e Saviani são tomadas como referência em muitos estudos e confirmadas nas pesquisas analisadas.

Os estudos publicados por Pena (201 1) e Baptaglin (2013) indicavam a existência de poucas pesquisas sobre o tema, mas teve acréscimo significativo a partir de 2010. Assim, consideramos que o mapeamento dos saberes docentes, por si só, é uma tarefa já realizada, não se constituindo em temas para novas pesquisas. Mesmo uma área que até, há pouco tempo, era carente de investigação os temas parecem haver se esgotado, com uma aparente replicação temática.

\section{Referências}

BAPTAGLIN, Leila Adriana. A educação profissional e tecnológica e a aprendizagem da docência: o que está sendo pesquisado nas produções acadêmico-científicas? In: CONGRESSO NACIONAL DE EDUCAÇÃO. 11; 2013, Curitiba, Anais... Curitiba: Pontifícia Universidade Católica do Paraná, 2013. Disponível em: educere.bruc.com.br/ ANAIS2013/pdf/7518_4366.pdf. Acesso em: 19 jun. 2014.

BARDIN, Laurence. Análise de conteúdo. Lisboa: Edições 70, 2002. 
DINIZ-PEREIRA, Júlio Emílio. A epistemologia da experiência na formação de professores: primeiras aproximações. Formação Docente, Belo Horizonte, v. 2, n. 2, p. 83-93, jan./ jul. 2010.

CLAUDINO, Jane Carla. Formação de professores para a educação técnica de nível médio - análise do Programa Especial de Formação Pedagógica da UTFPR. 2010, $142 f$. Dissertação (Mestrado em Educação) - Universidade Tecnológica Federal do Paraná, Curitiba, 2010.

GOMES, Sabrina Rodero F. O professor da educação profissional: formação e prática pedagógica. 2010. 204f. Dissertação (Mestrado em Educação) - Universidade Metodista de São Paulo, São Bernardo do Campo, 2010.

PENA, Geralda Aparecida de Carvalho. Formação docente e aprendizagem da docência: um olhar sobre a educação profissional. Educação em Perspectiva, Viçosa, v. 2, n. 1, p. 98-118, jan./jun. 2011.

ROMANOWSKI; Joana Paulin; ENS, Romilda Teodora. As pesquisas denominadas do tipo "estado da arte" em educação. Diálogo Educacional, Curitiba, v. 6, n. 19, p. 37-50, set./ dez. 2006.

REMOR, Clóvis Ricardo. Formação e profissionalização docente: análise do Programa Especial de Formação Pedagógica da UTFPR - Câmpus Medianeira. 2015. $120 f$. Dissertação (Mestrado em Educação) - Universidade Estadual Paulista, Marília, 2015.

SOARES, Juliana de Souza. Políticas para educação profissional: um estudo de caso sobre - Programa Especial de Formação Pedagógica de Docente em uma instituição de ensino técnico de Belo Horizonte. 2013. 177f. Dissertação (Mestrado em Educação) - Pontifícia Universidade Católica de Minas Gerais, Belo Horizonte, 2013.

SOUZA, Daniela Maysa de. Preparo do enfermeiro para a docência na educação profissional técnica de nível médio sob a ótica de Lee Shulman. 2013. 160f. Dissertação (Mestrado em Enfermagem) - Universidade Federal de Santa Catarina, Florianópolis, 2013. VIEIRA, Marilandi Maria Mascarello. Formação de professores da Educação Profissional: análise de produções acadêmicas. Revista Holos, Natal, v. 2, p. 243-258, 2018.

VIEIRA, Marilandi Maria Mascarello; ARAÚJO, Maria Cristina Pansera de; CARVALHO, Graça Simões de; PEREIRA, Rosa Branca Cameira Trancana. Como a comunidade científica portuguesa analisa a educação profissional. Tempos e Espaços em Educação, Sergipe, v. 11, n. 25, p. 33-48, abr./jun. 2018.

Prof ${ }^{a}$ Dra. Marilandi Maria Mascarello Vieira 
A formação de professores da educação profissional como objeto de estudo dos Programas de Pós-Graduação no Brasil

Instituto Federal de Educação, Ciência e Tecnologia do Rio Grande do Sul Câmpus Sertão

Núcleo de Ciências Humanas Grupo de Pesquisa Políticas Públicas e Formação de Professores para a Educação Básica e Profissional E-mail: marilandi.vieira@sertao.ifrs.edu.br

Profo Dr. Josimar de Aparecido Vieira Instituto Federal de Educação, Ciência e Tecnologia do Rio Grande do Sul Câmpus Sertão Núcleo de Ciências Humanas Grupo de Pesquisa Políticas Públicas e Formação de Professores para a Educação Básica e Profissional Email: josimar.vieira@sertao.ifrs.edu.br Profa Dra. Maria Cristina Pansera de Araújo Universidade Regional do Noroeste do Estado do Rio Grande do Sul Departamento de Ciências da Vida e Programa de Pós-Graduação em Educação nas Ciências Grupo Interdepartamental de Pesquisa sobre Educação em Ciências E-mail: pansera@unijui.edu.br

Recebido 22 maio 2018 Aceito 10 jul. 2018 


\section{Quadro}

\section{Dados sobre teses e dissertações acerca da formação de professores para EP - 2010 a 2017}

\begin{tabular}{|c|c|c|c|c|c|}
\hline Ano & Autor & Tí́tulo & Orientador & Instituição & $T / D$ \\
\hline 2017 & $\begin{array}{l}\text { Souza, } \\
\text { Alessandra M }\end{array}$ & $\begin{array}{l}\text { As metodologias ativas na prática de } \\
\text { docentes do ensino profissional. }\end{array}$ & $\begin{array}{l}\text { Passarelli, } \\
\text { Lilian Ghiuro }\end{array}$ & PUC-SP & $D$ \\
\hline 2016 & $\begin{array}{l}\text { Oliveira, } \\
\text { Anely Silva }\end{array}$ & $\begin{array}{l}\text { A formação do professor para a edu- } \\
\text { cação profissional: mapeando a } \\
\text { produção bibliográfica. }\end{array}$ & $\begin{array}{l}\text { Mororó, Leila } \\
\text { Pio }\end{array}$ & UESB & $D$ \\
\hline 2016 & $\begin{array}{l}\text { Damascena, } \\
\text { Edilza Alves }\end{array}$ & $\begin{array}{l}\text { Políticas de formação docente para a } \\
\text { educação profissional: análise em duas } \\
\text { escolas do Vale do Açu. }\end{array}$ & $\begin{array}{l}\text { Moura, Dante } \\
\text { Henrique }\end{array}$ & IFRN & $D$ \\
\hline 2016 & $\begin{array}{l}\text { Granvile, } \\
\text { Nilton César }\end{array}$ & $\begin{array}{l}\text { Saberes dos professores da educação } \\
\text { profissional técnica de nível médio em } \\
\text { enfermagem. }\end{array}$ & $\begin{array}{l}\text { Corrêa, } \\
\text { Adriana Katia }\end{array}$ & USP & $D$ \\
\hline 2016 & $\begin{array}{l}\text { Barros, } \\
\text { Rejane } \\
\text { Bezerra }\end{array}$ & $\begin{array}{l}\text { Formação e docência de professores } \\
\text { bacharéis na educação profissional e } \\
\text { tecnológica: uma interface dialógica } \\
\text { emancipatória. }\end{array}$ & $\begin{array}{l}\text { Ramalho, } \\
\text { Betania Leite }\end{array}$ & UFRN & $\mathrm{T}$ \\
\hline 2016 & $\begin{array}{l}\text { Santos, } \\
\text { Jocelaine } \\
\text { Oliveira dos; }\end{array}$ & $\begin{array}{l}\text { Tensões e contradições nos processos } \\
\text { identitários do professor da educação } \\
\text { básica, técnica e tecnológica. }\end{array}$ & $\begin{array}{l}\text { Follmann, José } \\
\text { Ivo }\end{array}$ & UNISINOS & $\mathrm{T}$ \\
\hline 2016 & $\begin{array}{l}\text { Santos, } \\
\text { Thalita Alves } \\
\text { dos }\end{array}$ & $\begin{array}{l}\text { De bacharel a professor: a construção } \\
\text { dos saberes pedagógicos na educação } \\
\text { profissional. }\end{array}$ & $\begin{array}{l}\text { Barros, Helena } \\
\text { Faria de }\end{array}$ & UNOESTE & $D$ \\
\hline 2016 & $\begin{array}{l}\text { Silva, Maria } \\
\text { do Socorro } \\
\text { da }\end{array}$ & $\begin{array}{l}\text { Políticas para a formação de profes- } \\
\text { sores no Brasil: em busca de indícios } \\
\text { de sua articulação com a educação } \\
\text { profissional. }\end{array}$ & $\begin{array}{l}\text { Silva, Lenina } \\
\text { Lopes Soares }\end{array}$ & IFRN & $D$ \\
\hline 2016 & $\begin{array}{l}\text { Aliança, } \\
\text { Priscila T. S. } \\
\text { M. da Silva }\end{array}$ & $\begin{array}{l}\text { O caminho feito ao andar: itinerários } \\
\text { formativos do professor bacharel no en- } \\
\text { sino médio integrado NATAL - RN. }\end{array}$ & $\begin{array}{l}\text { Souza, } \\
\text { Francisco das } \\
\text { Chagas Silva }\end{array}$ & IFRN & $D$ \\
\hline 2015 & $\begin{array}{l}\text { Rocha, Darlan } \\
\text { Oliveira }\end{array}$ & $\begin{array}{l}\text { Trajetórias de aprendizagem da docên- } \\
\text { cia de professores do ensino técnico em } \\
\text { nível médio. }\end{array}$ & $\begin{array}{l}\text { Mizukami, } \\
\text { Maria da G. } \\
\text { Nicoletti }\end{array}$ & MACKENZIE & D \\
\hline 2015 & $\begin{array}{l}\text { Oliveira, } \\
\text { Joselene Elias } \\
\text { de }\end{array}$ & $\begin{array}{l}\text { A profissionalidade do bacharel do- } \\
\text { cente da educação profissional e } \\
\text { tecnológica no Instituto Federal de } \\
\text { Educação, Ciência e Tecnologia do } \\
\text { Triângulo Mineiro-Câmpus Paracatu. }\end{array}$ & $\begin{array}{l}\text { Silva, Kátia } \\
\text { Augusta } \\
\text { Curado } \\
\text { Pinheiro C. da }\end{array}$ & UNB & $D$ \\
\hline
\end{tabular}


A formação de professores da educação profissional como objeto de estudo dos Programas de Pós-Graduação no Brasil

\begin{tabular}{|c|c|c|c|c|c|}
\hline 2015 & $\begin{array}{l}\text { Silva, Silvia } \\
\text { Helena dos } \\
\text { Santos Costa }\end{array}$ & $\begin{array}{l}\text { Quando engenheiros tornam-se profes- } \\
\text { sores: trajetórias formativas de docentes } \\
\text { do curso de engenharia elétrica (IFPB/ } \\
\text { João Pessoa). }\end{array}$ & $\begin{array}{l}\text { Souza, } \\
\text { Francisco das } \\
\text { Chagas Silva }\end{array}$ & IFRN & D \\
\hline 2015 & $\begin{array}{l}\text { Pires, Fabíula } \\
\text { Tatiane }\end{array}$ & $\begin{array}{l}\text { O saber docente que orienta a atuação } \\
\text { didática de professores de discipli- } \\
\text { nas técnicas na Educação Profissional } \\
\text { Técnica de Nível Médio. }\end{array}$ & $\begin{array}{l}\text { Oliveira, } \\
\text { Maria Rita } \\
\text { Neto Sales }\end{array}$ & CEFET - MG & D \\
\hline 2015 & $\begin{array}{l}\text { Remor, Clóvis } \\
\text { Ricardo }\end{array}$ & $\begin{array}{l}\text { Formação e profissionalização do- } \\
\text { cente: análise do Programa Especial } \\
\text { de Formação Pedagógica da UTFPR - } \\
\text { Câmpus Medianeira. }\end{array}$ & $\begin{array}{l}\text { Torres, Júlio } \\
\text { Cesar }\end{array}$ & UNESP & D \\
\hline 2015 & $\begin{array}{l}\text { Santos, } \\
\text { Lauriana } M \text {. } \\
\text { Costa }\end{array}$ & $\begin{array}{l}\text { Conhecimento pedagógico do } \\
\text { conteúdo de docentes da educa- } \\
\text { ção profissional de nível técnico em } \\
\text { enfermagem. }\end{array}$ & $\begin{array}{l}\text { Backes, Vânia } \\
\text { Marli Schubert }\end{array}$ & UFSC & $\Pi$ \\
\hline 2015 & $\begin{array}{l}\text { Wiggers, } \\
\text { Letícia Helena } \\
\text { F. F. Cruz }\end{array}$ & $\begin{array}{l}\text { Memórias e experiências do fazer-se } \\
\text { Professor na Educação Profissional: } \\
\text { Escola Técnica Federal de Santa } \\
\text { Catarina-ETFSC (1968-2010). }\end{array}$ & $\begin{array}{l}\text { Paim, Elison } \\
\text { Antônio }\end{array}$ & UFSC & D \\
\hline 2015 & $\begin{array}{l}\text { Souza, Clésio } \\
\text { Feliciano de }\end{array}$ & $\begin{array}{l}\text { Política educacional de formação de } \\
\text { professores do ensino técnico profissio- } \\
\text { nal no âmbito da unidade integrada } \\
\text { SESI/SENAl no município de Rio Verde } \\
\text { - Goiás (2006 - 2013). }\end{array}$ & $\begin{array}{l}\text { Carmo, } \\
\text { Jefferson } \\
\text { Carriello do }\end{array}$ & UCDB & D \\
\hline 2014 & $\begin{array}{l}\text { Araújo, } \\
\text { Wanderson P. }\end{array}$ & $\begin{array}{l}\text { A formação docente para a educação } \\
\text { profissional e tecnológica no IFNMG - } \\
\text { Câmpus Januária. }\end{array}$ & $\begin{array}{l}\text { Viana, Cleide } \\
\text { Maria Q. } \\
\text { Quixadá. }\end{array}$ & UNB & D \\
\hline 2014 & \begin{tabular}{|l|} 
Pena, \\
Geralda \\
Aparecida de \\
Carvalho \\
\end{tabular} & $\begin{array}{l}\text { Docência na educação profissional e } \\
\text { tecnológica: conhecimentos, práticas e } \\
\text { desafios de professores de cursos técni- } \\
\text { cos na Rede Federal. }\end{array}$ & $\begin{array}{l}\text { Santos, Lucíola } \\
\text { Licínio de C. P. }\end{array}$ & UFMG & T \\
\hline 2014 & $\begin{array}{l}\text { Silva, } \\
\text { Filomena } \\
\text { L. Gossler } \\
\text { Rodrigues da }\end{array}$ & $\begin{array}{l}\text { Identidade profissional dos professores } \\
\text { da educação profissional técnica de ní- } \\
\text { vel médio no Brasil e em Santa Catarina: } \\
\text { desafios para a sua formação. }\end{array}$ & Scheibe, Leda & UFSC & T \\
\hline 2014 & $\begin{array}{l}\text { Pinto, Lina } \\
\text { Márcia de C. } \\
\text { da Silva }\end{array}$ & $\begin{array}{l}\text { A constituição do professor pelo traba- } \\
\text { lho docente na educação profissional: } \\
\text { o caso do IFMT - Câmpus Cuiabá - } \\
\text { Octayde Jorge da Silva. }\end{array}$ & $\begin{array}{l}\text { Ribeiro, Jorge } \\
\text { Alberto Rosa }\end{array}$ & UFRGS & T \\
\hline
\end{tabular}




\begin{tabular}{|c|c|c|c|c|c|}
\hline 2014 & $\begin{array}{l}\text { Faria, } \\
\text { Vanessa } \\
\text { Piedade } \\
\text { Gontijo }\end{array}$ & $\begin{array}{l}\text { Políticas públicas para a educação } \\
\text { profissional: estudo da formação/ } \\
\text { profissionalização e do trabalho do } \\
\text { professor do Programa Especial de } \\
\text { Formação Pedagógica de Docentes. }\end{array}$ & $\begin{array}{l}\text { Marques, } \\
\text { Stela Maria } \\
\text { Fernandes }\end{array}$ & PUC MINAS & $D$ \\
\hline 2013 & $\begin{array}{l}\text { Souza, } \\
\text { Marco } \\
\text { Antônio } \\
\text { Simões de }\end{array}$ & $\begin{array}{l}\text { A formação de professores para a edu- } \\
\text { cação profissional e tecnológica na } \\
\text { perspectiva da educação ambiental: } \\
\text { desaceleração do tempo e desfragmen- } \\
\text { tação do currículo. }\end{array}$ & $\begin{array}{l}\text { Galiazzi, } \\
\text { Maria do } \\
\text { Carmo }\end{array}$ & FURG & $\mathrm{T}$ \\
\hline 2013 & $\begin{array}{l}\text { Nascimento, } \\
\text { Lauriane Alves } \\
\text { do }\end{array}$ & $\begin{array}{l}\text { Saberes docentes da educação pro- } \\
\text { fissional técnica de nível médio do } \\
\text { IFPI: a construção de uma docência } \\
\text { qualificada. }\end{array}$ & $\begin{array}{l}\text { Forster, Mari } \\
\text { Margarete dos } \\
\text { Santos }\end{array}$ & UNISINOS & $D$ \\
\hline 2013 & $\begin{array}{l}\text { Costa, Bruno } \\
\text { Silva }\end{array}$ & $\begin{array}{l}\text { Influência da formação pedagógica na } \\
\text { prática do docente de EPT. }\end{array}$ & $\begin{array}{l}\text { Carvalho, } \\
\text { Olgamir } \\
\text { Francisco de }\end{array}$ & UNB & $D$ \\
\hline 2013 & $\begin{array}{l}\text { Loureiro, Luis } \\
\text { Humberto } \\
\text { Ferrari }\end{array}$ & $\begin{array}{l}\text { Como nos tornamos formadores na } \\
\text { roda da licenciatura para a educação } \\
\text { profissional e tecnológica. }\end{array}$ & $\begin{array}{l}\text { Galiazzi, } \\
\text { Maria do } \\
\text { Carmo }\end{array}$ & FURG & $\mathrm{T}$ \\
\hline 2013 & $\begin{array}{l}\text { Santos, Enoi } \\
\text { Maria da Luz }\end{array}$ & $\begin{array}{l}\text { A autoformação docente no ensino } \\
\text { técnico profissional na interface com } \\
\text { a prática pedagógica: significados e } \\
\text { potencialidades. }\end{array}$ & $\begin{array}{l}\text { Cunha, Maria } \\
\text { Isabel da }\end{array}$ & UNISINOS & D \\
\hline 2013 & $\begin{array}{l}\text { Yamamoto, } \\
\text { Fernanda A. }\end{array}$ & $\begin{array}{l}\text { Aprendizagem da docência de profes- } \\
\text { sores da educação profissional. }\end{array}$ & $\begin{array}{l}\text { Mizukami, } \\
\text { Maria da } G . \\
\text { Nicoletti }\end{array}$ & UPM & D \\
\hline 2013 & $\begin{array}{l}\text { Soares, } \\
\text { Juliana de } \\
\text { Souza }\end{array}$ & $\begin{array}{l}\text { Políticas para educação profissional: } \\
\text { um estudo de caso sobre o Programa } \\
\text { Especial de Formação Pedagógica de } \\
\text { Docente em uma Instituição de Ensino } \\
\text { Técnico de Belo Horizonte. }\end{array}$ & $\begin{array}{l}\text { Oliveira, } \\
\text { Maria } \\
\text { Auxiliadora } \\
\text { Monteiro }\end{array}$ & PUC MINAS & D \\
\hline 2013 & $\begin{array}{l}\text { Souza, } \\
\text { Daniela } \\
\text { Maysa de }\end{array}$ & $\begin{array}{l}\text { Preparo do enfermeiro para a docência } \\
\text { na educação profissional técnica de ní- } \\
\text { vel médio sob a ótica de Lee Shulman. }\end{array}$ & $\begin{array}{l}\text { Backes, Vânia } \\
\text { Marli Schubert }\end{array}$ & UFSC & D \\
\hline 2013 & $\begin{array}{l}\text { Frozoni, } \\
\text { Raquel } \\
\text { Cequalini }\end{array}$ & $\begin{array}{l}\text { Identidade profissional e perfil dos } \\
\text { professores dos cursos de educação } \\
\text { profissional técnica de nível médio em } \\
\text { enfermagem de um município do inte- } \\
\text { rior do Estado de SP. }\end{array}$ & $\begin{array}{l}\text { Souza, Maria } \\
\text { Conceição } \\
\text { Bernardo de } \\
\text { Mello e }\end{array}$ & USP & $D$ \\
\hline
\end{tabular}


A formação de professores da educação profissional como objeto de estudo dos Programas de Pós-Graduação no Brasil

\begin{tabular}{|c|c|c|c|c|c|}
\hline 2012 & $\begin{array}{l}\text { Heckler, } \\
\text { Gisele Lopes }\end{array}$ & $\begin{array}{l}\text { A especificidade do trabalho docente } \\
\text { no PROEJA: um estudo sobre a experi- } \\
\text { ência do Instituto Federal de Educação, } \\
\text { Ciência e Tecnologia Sul-Rio-Grandense } \\
\text { Câmpus Sapucaia do Sul/RS. }\end{array}$ & Eggert, Edla & UNISINOS & D \\
\hline 2012 & $\begin{array}{l}\text { Brito, } \\
\text { Antoinette } \\
\text { Francês }\end{array}$ & $\begin{array}{l}\text { Formação e condição de trabalho dos } \\
\text { professores da educação de jovens e } \\
\text { adultos. PROEJA: um estudo de caso } \\
\text { realizado no IFPA, Câmpus de Belém. }\end{array}$ & $\begin{array}{l}\text { Sousa, } \\
\text { Antônia de } \\
\text { Abreu }\end{array}$ & UFC & $D$ \\
\hline 2012 & $\begin{array}{l}\text { Cardoso, } \\
\text { Aliana A. }\end{array}$ & $\begin{array}{l}\text { Professores? Sim! Os saberes docen- } \\
\text { tes e os professores da Educação } \\
\text { Profissional. }\end{array}$ & $\begin{array}{l}\text { Del Pino, } \\
\text { Mauro Burkert }\end{array}$ & UFPEL & D \\
\hline 2012 & $\begin{array}{l}\text { Helmer, Ester } \\
\text { Almeida }\end{array}$ & $\begin{array}{l}\text { O processo de construção da profissio- } \\
\text { nalidade docente no Instituto Federal } \\
\text { de educação, Ciência e Tecnologia de } \\
\text { São Paulo. }\end{array}$ & $\begin{array}{l}\text { Reyes, } \\
\text { Cláudia } \\
\text { Raimundo }\end{array}$ & UFSCAR & $\mathrm{T}$ \\
\hline 2012 & $\begin{array}{l}\text { Fernandes, } \\
\text { Natal Lânia } \\
\text { Roque }\end{array}$ & $\begin{array}{l}\text { Processos identitários docentes: percur- } \\
\text { sos de vida e de trabalho no contexto do } \\
\text { Proeja do Instituto Federal de Educação, } \\
\text { Ciência e Tecnologia do Ceará. }\end{array}$ & $\begin{array}{l}\text { Barreto, Sonia } \\
\text { Pereira }\end{array}$ & UFC & $\mathrm{T}$ \\
\hline 2012 & $\begin{array}{l}\text { Moreira, } \\
\text { Alexandre }\end{array}$ & $\begin{array}{l}\text { Formação e atuação do bacharel- } \\
\text {-professor na área de telecomunicações } \\
\text { do Instituto Federal de Santa Catarina: } \\
\text { Campos São José. }\end{array}$ & $\begin{array}{l}\text { Neto, Jorge } \\
\text { Megid }\end{array}$ & UNICAMP & D \\
\hline 2012 & $\begin{array}{l}\text { Santos, } \\
\text { Adriana P. Q. } \\
\text { R. S. O. }\end{array}$ & $\begin{array}{l}\text { ltinerâncias Rizoéticas: saberes e forma- } \\
\text { ção docente na Educação Profissional e } \\
\text { Tecnológica (EPT). }\end{array}$ & $\begin{array}{l}\text { Fartes, Vera } \\
\text { Lúcia Bueno }\end{array}$ & UFBA & $\mathrm{T}$ \\
\hline 2012 & $\begin{array}{l}\text { Costa, Maria } \\
\text { Adélia da }\end{array}$ & $\begin{array}{l}\text { Políticas de formação de professores } \\
\text { para a educação profissional e tecnoló- } \\
\text { gica: cenários contemporâneos. }\end{array}$ & $\begin{array}{l}\text { França, } \\
\text { Robson Luiz de }\end{array}$ & UFU & $\mathrm{T}$ \\
\hline 2012 & $\begin{array}{l}\text { Fortes, Maria } \\
\text { Carolina }\end{array}$ & $\begin{array}{l}\text { Entrelaçamentos de vidas: a cons- } \\
\text { tituição da docência na educação } \\
\text { profissional e tecnológica. }\end{array}$ & $\begin{array}{l}\text { Abrahão, } \\
\text { Maria Helena } \\
\text { M.Barreto } \\
\end{array}$ & PUC-RS & $\mathrm{T}$ \\
\hline 2012 & $\begin{array}{l}\text { Lima, } \\
\text { Fernanda B. } \\
\text { Goncalves }\end{array}$ & $\begin{array}{l}\text { A formação de professores nos Institutos } \\
\text { Federais de Educação, Ciência e } \\
\text { Tecnologia: um estudo da concepção } \\
\text { política. }\end{array}$ & $\begin{array}{l}\text { Silva, Katia } \\
\text { Augusta C. } \\
\text { Pinheiro C. da }\end{array}$ & UNB & D \\
\hline 2012 & $\begin{array}{l}\text { Pereira, } \\
\text { Andrea F. } \\
\text { Garcia }\end{array}$ & $\begin{array}{l}\text { Representações sociais de professores } \\
\text { da educação profissional sobre a iden- } \\
\text { tidade docente. }\end{array}$ & $\begin{array}{l}\text { Abdalla, } \\
\text { Maria de } \\
\text { Fátima } \\
\text { Barbosa }\end{array}$ & UNISANTOS & D \\
\hline 2011 & $\begin{array}{l}\text { Urbanetz, } \\
\text { Sandra }\end{array}$ & $\begin{array}{l}\text { A constituição do docente para a edu- } \\
\text { cação profissional. }\end{array}$ & $\begin{array}{l}\text { Kuenzer, } \\
\text { Acácia Z. }\end{array}$ & UFPR & $\mathrm{T}$ \\
\hline
\end{tabular}


Marilandi Maria Mascarello Vieira | Josimar de Aparecido Vieira | Maria Cristina Pansera de Araújo

\begin{tabular}{|c|c|c|c|c|c|}
\hline 2011 & $\begin{array}{l}\text { Barbacovi, } \\
\text { Lecir Jacinto }\end{array}$ & $\begin{array}{l}\text { O professor de educação profissional e } \\
\text { a conectividade orgânica entre forma- } \\
\text { ção e prática docente. }\end{array}$ & $\begin{array}{l}\text { Heijmans, } \\
\text { Rosemary } \\
\text { Dore }\end{array}$ & UFMG & $\mathrm{T}$ \\
\hline 2011 & $\begin{array}{l}\text { Simionato, } \\
\text { Margareth F. }\end{array}$ & $\begin{array}{l}\text { A formação do professor do ensino téc- } \\
\text { nico e a cultura docente. }\end{array}$ & $\begin{array}{l}\text { Ribeiro, Jorge } \\
\text { Alberto Rosa }\end{array}$ & UFRGS & $\mathrm{T}$ \\
\hline 2011 & $\begin{array}{l}\text { Silva, Carla } \\
\text { O. Balestro }\end{array}$ & $\begin{array}{l}\text { Admirando o professor de formação } \\
\text { técnica: o fazer-se docente no encontro } \\
\text { com o PROEJA. }\end{array}$ & $\begin{array}{l}\text { Franzoi, Naira } \\
\text { Lisboa }\end{array}$ & UFGRS & D \\
\hline 2011 & $\begin{array}{l}\text { Martins, } \\
\text { Leticia A. }\end{array}$ & $\begin{array}{l}\text { Trajetórias de constituição da docência } \\
\text { na educação profissional. }\end{array}$ & $\begin{array}{l}\text { Barolli, } \\
\text { Elisabeth }\end{array}$ & UNICAMP & D \\
\hline 2011 & $\begin{array}{l}\text { Orso, } \\
\text { Ana Paula } \\
\text { Grochocki }\end{array}$ & $\begin{array}{l}\text { As políticas educacionais de formação } \\
\text { de professores dos cursos técnicos em } \\
\text { nível médio: cursos profissionalizantes } \\
\text { no Paraná (1971 2008). }\end{array}$ & $\begin{array}{l}\text { Miguel, Maria } \\
\text { Elisabeth } \\
\text { Blanck }\end{array}$ & PUC-PR & D \\
\hline 2010 & $\begin{array}{l}\text { Mascarello, } \\
\text { Karen } \\
\text { Gregory }\end{array}$ & $\begin{array}{l}\text { Entre o ontem e o amanhã: análise } \\
\text { das razões da escolha de profissionais } \\
\text { pelo trabalho docente na Educação } \\
\text { Profissional. }\end{array}$ & $\begin{array}{l}\text { Fischer, Maria } \\
\text { Clara Bueno }\end{array}$ & UNISINOS & D \\
\hline 2010 & $\begin{array}{l}\text { Gomes, } \\
\text { Sabrina R. F. }\end{array}$ & $\begin{array}{l}\text { O professor da educação profissional: } \\
\text { formação e prática pedagógica. }\end{array}$ & $\begin{array}{l}\text { Demartini, } \\
\text { Zeila de. } \\
\text { Fabri }\end{array}$ & UMESP & D \\
\hline 2010 & $\begin{array}{l}\text { Ferreira, } \\
\text { Angelita da } \\
\text { R. } \bigcirc \text {. }\end{array}$ & $\begin{array}{l}\text { Os professores da educação profis- } \\
\text { sional: sujeitos (re)inventados pela } \\
\text { docência. }\end{array}$ & $\begin{array}{l}\text { Mosquera, } \\
\text { Juan J.Mouriño }\end{array}$ & PUC-RS & D \\
\hline 2010 & $\begin{array}{l}\text { Claudino, } \\
\text { Jane Carla }\end{array}$ & $\begin{array}{l}\text { Formação de Professores para a } \\
\text { Educação Técnica de Nível Médio } \\
\text { - Análise do Programa Especial de } \\
\text { Formação Pedagógica da UTFPR. }\end{array}$ & $\begin{array}{l}\text { Lima Filho, } \\
\text { Domingos Leite }\end{array}$ & UTFPR & D \\
\hline 2010 & $\begin{array}{l}\text { Scirea, } \\
\text { Marlene M. } \\
\text { Fumagali }\end{array}$ & $\begin{array}{l}\text { Formação de professores para a educa- } \\
\text { ção profissional técnica de nível médio. }\end{array}$ & Scheibe, Leda & UNOESC & D \\
\hline 2010 & $\begin{array}{l}\text { Vieira, } \\
\text { Sebastião } \\
\text { Gândara }\end{array}$ & $\begin{array}{l}\text { A formação de professores de ensino } \\
\text { técnico de nível médio estadual e suas } \\
\text { relações com o arranjo produtivo local } \\
\text { na cidade de Jahu. }\end{array}$ & $\begin{array}{l}\text { Quaglio, } \\
\text { Paschoal }\end{array}$ & UNESP & D \\
\hline 2010 & $\begin{array}{l}\text { Silva Junior, } \\
\text { Geraldo S. }\end{array}$ & $\begin{array}{l}\text { Saberes da docência de professores da } \\
\text { educação profissional tecnológica. }\end{array}$ & $\begin{array}{l}\text { Gariglio, José } \\
\text { Ângelo }\end{array}$ & CEFET - MG & D \\
\hline 2010 & $\begin{array}{l}\text { Milanelli, } \\
\text { Hania }\end{array}$ & $\begin{array}{l}\text { Ser docente: um estudo sobre as repre- } \\
\text { sentações sociais de enfermeiros que } \\
\text { atuam como professores no ensino téc- } \\
\text { nico de enfermagem. }\end{array}$ & $\begin{array}{l}\text { Duran, Marília } \\
\text { Claret Geraes }\end{array}$ & UMESP & D \\
\hline
\end{tabular}

Fonte: produzido pelos autores com base nos trabalhos localizados no banco de teses e dissertações da CAPES, no IBICT e nos sites dos Programas de Pós-Graduação. 